\title{
RECENT ADVANCES IN
}

\section{REGIONAL CLIMATE SYSTEM MODELING}

\author{
AND \\ CLIMATE CHANGE ANALYSES OF EXTREME HEAT
}

Prepared For:

California Energy Commission

Public Interest Energy Research Program

Prepared By:

Norman L. Miller

Atmosphere and Ocean Sciences Group

Earth Sciences Division, Berkeley National Laboratory

Technical Report LBNL-XXXX

September 2004 


\begin{abstract}
During the period May 2003 to May 2004, there were two CEC/PIER funded primary research activities by the Atmosphere and Ocean Sciences Group/Earth Science Division at LBNL. These activities are the implementation and testing of the National Center for Atmospheric Research Community Land Model (CLM) into MM5, and the analysis of extreme heat days under a new set of climate simulations. The new version of MM5, MM5-CLM, has been tested for a 90 day snowmelt period in the northwestern U.S. Results show that this new code upgrade, as compared to the MM5-NOAH, has improved snowmelt, temperature, and precipitation when compared to observations. These are due in part to a subgrid scheme, advanced snow processes, and advanced vegetation. The climate change analysis is the upper and lower IPCC Special Report on Emission Scenarios, representing fossil fuel intensive and energy conserving future emission scenarios, and medium and low sensitivity Global Climate Models. Results indicate that California cities will see increases in the number of heat wave and temperature threshold days from two to six times. These results may be viewed as potential outcomes based on today's decisions on emissions.
\end{abstract}




\section{CONTENTS}

$\begin{array}{ll}\text { ABSTRACT } & 2\end{array}$

1.0 INTRODUCTION 4

2.0 REGIONAL CLIMATE SYSTEM MODEL ADVANCES 4

$\begin{array}{ll}\text { 2.1 DESCRIPTION } & 4\end{array}$

2.2 MODEL SIMULATION AND ANALYSIS

$\begin{array}{ll}\text { 2.3 NEXT STEPS } & 6\end{array}$

3.0 CLIMATE CHANGE ANALYSES OF EXTREME HEAT DAYS 6

3.1 EMISSION SCENARIOS AND CLIMATE CHANGE 6

$\begin{array}{ll}\text { 3.2 EXTREME HEAT DAYS } & 7\end{array}$

3.3 HEAT WAVES AND EXTREME HEAT EVENTS 8

$\begin{array}{ll}\text { 4.0 REFERENCES } & 10\end{array}$

$\begin{array}{ll}\text { 5.0 ACKNOWLEDGEMENTS } & 10\end{array}$

$\begin{array}{lr}\text { 6.0 FIGURES AND TABLE } & 11\end{array}$

$\begin{array}{ll}\text { 7.0 PRESENTATIONS } & 15\end{array}$ 


\subsection{INTRODUCTION}

During the period May 2003 to May 2004 the CEC provided $\$ 100,000$ support for climate change research in the Atmosphere and Ocean Sciences Group/Earth Science Division at LBNL. The CEC support contributed to regional climate model development and testing, climate change heat impacts analyses, and participation in a number of planning meetings and workshops. This report summarizes these activities and provides a list of peer reviewed publications, submissions, and presentations.

\subsection{REGIONAL CLIMATE SYSTEM MODEL ADVANCES}

\subsection{DESCRIPTION}

New model development and testing based on the Penn State/National Center for Atmospheric Research (NCAR) Mesoscale Model version 5 (MM5) and the NCAR Community Land Surface Model (CLM) has been completed. The standard release version of the MM5 code includes the NOAH land surface model within of its land surface model settings. This has been advanced by the Atmosphere and Ocean Sciences Group at Berkeley Lab with the implementation of CLM, a more advanced land surface model. The most significant improvements based on this implementation of CLM are seen via its sub-grid land surface structure, 10 soil layers, 5 snow layers, topographically controlled hydrology, biogeochemistry, and vegetation dynamics. The new MM5-CLM was tested for a snowmelt period which resulted in a significant improvement in the simulation of state variables (Jin and Miller 2004). Model parallelization has advanced with tests on the National Energy Research Scientific computing Center's Seaborg computer, where a series of benchmark simulations have been completed.

\subsection{MODEL SIMULATION AND ANALYSIS}

A 90-day simulation was generated using MM5-CLM at $60 \mathrm{~km}$ and $20 \mathrm{~km}$ resolutions for the Northwestern U.S., with initial and lateral boundary conditions provided by the 6hourly NCEP/NCAR reanalysis. Due to the poor quality of the reanalyzed snow data by the NCEP/NCAR, the snowpack in the coupled model was initialized by the automatically observed Snowpack Telemetry (SNOTEL) data and the NASA Land Data Assimilation Systems (LDAS) data, where the LDAS data is a mixture of observations and the model simulations.

The observations from several sources were used to compare with the model output. The SNOTEL data include daily snowdepth, surface air temperature, and precipitation. This dataset was downloaded from the Western Regional Climate Center (www.wrcc.dri.edu). 
The U.S. Cooperative Meteorological Station data obtained from the NCAR consists of 6-hourly temperature and precipitation. The $5 \mathrm{~km} \times 5 \mathrm{~km}$ MODIS/Terra snow cover data and the $4 \mathrm{~km} \times 4 \mathrm{~km}$ SeaWiFS surface albedo data were ordered from NASA. Two sets of $60 \mathrm{~km}$ and $20 \mathrm{~km}$ hourly model output from March 1 to May 31, 2002 were produced by MM5-NOAH and MM5-CLM (denoted as Old and New, respectively in the figures). Only the $20 \mathrm{~km}$ resolution data were analyzed.

The model output from the original version of MM5 with the NOAH land surface model indicates that the snowdepth is dramatically underestimated when compared to the observed SNOTEL data (Figure 1). In MM5-NOAH, the snowpack is seen to have a faster snowmelt from the very beginning of the simulation, and all the snow mass melts out before May 10, when more than $400 \mathrm{~mm}$ of the snowdepth is observed at the SNOTEL stations. Detailed analyses show that during the snow season, the snow surface receives an exaggerated amount of solar radiation due to the inaccurate treatment of the vegetation coverage in the NOAH model, resulting in a faster snowmelt. The simplified snow physics also contributes to the poorly simulated snowpack. Therefore, with the implementation of the advanced CLM in MM5, which has more realistic and sophisticated snow and vegetation schemes, the snowpack simulation is significantly improved (Figure 1). The faster snow melt in the MM5-NOAH simulation leads to a quicker snow cover retreat in the late snow melt stage than MM5-CLM, which is close to the MODIS/Terra satellite data derived snow cover area, especially in the near west coast regions (Figure 2).

Figure 3 shows the comparison of the observations and the simulations produced by both MM5-NOAH and MM5-CLM. This figure indicates that the both versions of MM5 are able to generate good simulations for the surface air temperature. However, MM5-NOAH produces a lower temperature in the early phase of the snow melt than the observations averaged over the SNOTEL stations. The lower temperature is found to result from a larger amount of longwave radiation emission from the snow surface. In MM5-NOAH, the snow surface directly exchanges long-wave radiation with the atmosphere without going through the vegetation, possibly a reason for the greater longwave radiation loss from the snow surface, especially during early spring season nights when air temperature is often lower than vegetation temperature.

The precipitation simulation averaged over the SNOTEL station locations indicates that both MM5-CLM and MM5-NOAH realistically reproduce the observed precipitation at these locations (Fig. 4). Nevertheless, stronger precipitation generated by MM5-NOAH during May, 1998 is seen. Further investigation finds that the exaggerated precipitation is caused by stronger convection resulting from an unstable atmosphere. The unstable atmosphere is due to the intensified surface evaporation and higher surface temperature caused by the earlier snowmelt in MM5-NOAH. The coupling of MM5 and CLM successfully suppresses the overestimated convective precipitation, because MM5-CLM produces a more stable atmosphere due to the accurate simulation of the snowpack, which restricts the convection and decreases the precipitation. 
The implementation of the sub-grid land surface structure in MM5-CLM significantly improves the model's ability to describing subgrid heterogeneity in land surface characteristics. Figure 5 shows the $4 \mathrm{~km} \mathrm{x} 4 \mathrm{~km}$ SeaWiFS satellite surface albedo and the simulated surface albedo at the $20 \mathrm{~km}$ resolution by MM5-CLM and MM5-NOAH. Although both models give similar geographic distributions of the surface albedo to the observations, MM5-CLM provides more detailed information of the surface albedo distribution due much to the introduction of the sub-grid land surface structure. At the same time, the more sophisticated albedo algorithm in MM5-CLM further improves the surface albedo simulation, when compared to that in MM5-NOAH.

\subsection{NEXT STEPS}

At present the new MM5-CLM code is undergoing additional tests and parallelization benchmarking on Seaborg. Production runs are being prepared to coordinate initial and lateral boundary conditions and simulations periods with those of the California Regional Model Intercomparison and the North America Regional Climate Change and Assessment Programs.

\subsection{CLIMATE CHANGE ANALYSES OF EXTREME HEAT DAYS}

In early 2004, a group of researchers advanced new approach to climate change analysis evaluated impacts based on different emissions scenarios (Hayhoe et al. 2004). This departure from evaluations of climate projections using only the IS92A emission shows outcomes as a result of emissions pathways. In this study, an upper and lower set of emissions projections from the IPCC Special Report on Emissions Scenarios (SRES) were selected. As a contribution to this work the Atmosphere and Ocean Sciences Group/Earth Science Division at LBNL analyzed extreme heat days and heat wave frequency of occurrence.

\subsection{Emission Scenarios and Climate Projections}

The projections of increases in extreme heat presented are based on climate projections from two of the latest generation of global climate or general circulation models (GCMs): the Parallel Climate Model (PCM), recently developed at the U.S. National Center for Atmospheric Research (Washington et al. 2000), and the HadCM3 model, developed at U.K. Meteorological Office's Hadley Centre for Climate Modeling (Pope et al. 2000). HadCM3 and PCM are two of the highest resolution and most recently-updated GCMs available, and the only two to successfully reproduce observed global climate variations over the past century without flux adjustment.

Model climate sensitivity determines the magnitude of the modelled increase in temperature in response to human emissions of greenhouse gases (GHGs). For the PCM model, climate sensitivity is at the low end of the range while HadCM3 sensitivity is in 
the middle of the range. For the western region of North America, HadCM3 and PCM projections together cover from the low end of the temperature range up to approximately $50 \%$ (for winter) and $>80 \%$ (other seasons) of the change in temperature projected by the 7 AOGCMs and 4 scenarios (Ruosteenoja et al., 2003). Estimates of potential changes in temperature are therefore on the conservative side, although not overly so for the warmer season, when extreme heat events occur.

Climate projections (Fig. 6) correspond to the highest and lowest scenarios from the Intergovernmental Panel on Climate Change's Special Report on Emissions Scenarios (IPCC SRES, Nakicenovic et al., 2000). These describe internally consistent pathways of future greenhouse gas (GHG) emissions. SRES scenarios cover a wide range of alternative futures based on projections of economic growth, technology, energy intensity, and population. The SRES scenarios can be viewed as possible futures, with the actual path depending on technology, economic development and political will. The A1fi (higher) and B1 (lower) scenarios used in this study bracket the range of SRES scenarios, and can be thought of as lower and higher bounds that encompass most, but not all, potential non-intervention emissions futures. At the higher end, rapid introduction of new technologies, extensive economic globalization, and a fossil-intensive energy path causes Alfi $\mathrm{CO}_{2}$ emissions to climb throughout the century, reaching almost $30 \mathrm{Gt} / \mathrm{yr}$ or 6 times 1990 levels by 2100 (Houghton et al. 2001). Emissions under the B1 scenario are lower, based on a world that transitions relatively rapidly to service and information economies. $\mathrm{CO}_{2}$ emissions in the $\mathrm{B} 1$ scenario peak at just below $10 \mathrm{Gt} / \mathrm{yr}$ - around two times 1990 levels - at mid-century and decline slowly to below current-day levels.

\subsection{Extreme Heat Days}

Changes in local temperature extremes were evaluated based on calculated exceedance probability (EP) analyses, using the distribution of daily maximum temperatures downscaled to representative locations (Miller et al., 2003). Non-exceedance probabilities define a given temperature for which the probability exists that $\mathrm{X}$ percent of days throughout the year will fall below that temperature. For example, if the $35^{\circ} \mathrm{C} \mathrm{EP}$ averages 95 percent for the period 2070-2099, this means that an average of 95 percent or $\sim 347$ days per year are likely to lie below $35^{\circ} \mathrm{C}$. Conversely, $5 \%$ of days ( $\sim 18$ days per year) will lie above $35^{\circ} \mathrm{C}$.

A measure of the projected change in maximum temperature extremes is given by the shift in the 95 percent non-exceedance values (i.e., the 5 percent highest mean maximum daily temperatures for each decade or roughly 18 days per year with temperatures exceeding this amount). Under current-day conditions, the $95 \%$ non-exceedance temperature threshold is $32^{\circ} \mathrm{C}$ for temperate, coastal Los Angeles and $37^{\circ} \mathrm{C}$ for warmer, inland Sacramento. This means that $5 \%$ of days in Los Angeles are currently above $32^{\circ} \mathrm{C}$, while $5 \%$ of days in Sacramento are above $37^{\circ} \mathrm{C}$. The $95 \%$ non-exceedance for San Francisco is $26{ }^{\circ} \mathrm{C}$, San Bernadino is $39.5^{\circ} \mathrm{C}$, Fresno is $39.5{ }^{\circ} \mathrm{C}$, and El Centro is $44{ }^{\circ} \mathrm{C}$.

Los Angeles, with its rapidly increasing population, has a dramatic shift in heat EP for future scenarios (Fig. 7). For the 2090s, the current-day $5 \%$ heat threshold of $32^{\circ} \mathrm{C}$ is exceeded by $14-21 \%$ of days under the B1 scenario and $25-38 \%$ under A1fi. The state capitol, Sacramento, is also expected to see strong shifts in the number of days that 
exceed the current-day $5 \%$ heat exceedance threshold of $37^{\circ} \mathrm{C}$ (Fig. 7). Under the B1 emissions scenario, $14-19 \%$ of days will exceed $37^{\circ} \mathrm{C}$ while under $\mathrm{A} 1 \mathrm{fi}$, the percentage grows to $27-33 \%$. Similarly, the 5\% value for San Francisco is exceeded $18-25 \%$ under B1 and 32-44\% under A1fi, San Bernadino is exceeded 12-18\% under B1 and 24-30\% under A1fi, Fresno is exceeded 13-19\% under B1 and 24-31\% under A1fi, and El Centro is exceeded $10-13 \%$ under B1 and $20-21 \%$ under A1fi toward the end of the century. This means that under the higher emissions scenario, up to one third of the year in both Los Angeles and Sacramento could be under heat threat conditions which currently occur an average of only $5 \%$ or $\sim 18$ days per year.

Exceedance probabilities can also be used to measure the number of days on which temperatures exceed a standardized threshold of $32^{\circ} \mathrm{C}$. During the $1990 \mathrm{~s}$, coastal Los Angeles experienced such temperatures $5 \%$ of the year, while the $32^{\circ} \mathrm{C}$ threshold was exceeded in inland Sacramento $22 \%$ of the year. By end-of-century, Los Angeles is projected to see temperatures exceed $32^{\circ} \mathrm{C}$ on as many as $14-21 \%$ or $50-80$ days/year under the B1 scenario and $26-37 \%$ or $95-135$ days/year under A1fi; in either case, this constitutes a dramatic increase over the 18 days/year experienced during the reference period. For Sacramento, $32^{\circ} \mathrm{C}$ is likely to be exceeded one-third of the year $(30-33 \%$ or about 110-120 days/year) under the B1 scenario and two-fifths of the year $(39-43 \%$ or about 140-155 days/year) under A1fi, both a significant increase over the $\sim 80$ days/yr experienced during the 1990 s.

\subsection{Heat Waves and Extreme Heat Events}

The frequency, length, and intensity of heat waves increase under all simulations, most dramatically under the A1fi scenario. By mid-century, significant differences are evident between the outcomes of the higher and the lower emissions scenario, while by end-ofcentury, these differences intensify and a clear disparity emerges between the more temperate, coastal Los Angeles and San Francisco vs. the hotter, inland cities of Fresno, Sacramento and San Bernadino/Riverside.

Heat waves are defined here as occurring an average of three times per year during the reference period 1961-1990 and lasting a minimum of three consecutive days with no upper limit on duration. Temperature thresholds used to determine a local heat wave vary by location, being defined by weather patterns over that location during the reference period, as shown in Table 1.

Although determined independently, the values resemble the 5\% exceedance probabilities determined in the previous analysis. A region-specific approach was selected over a standardized temperature threshold approach to defining heat waves, since the latter is problematic for regions such as California where local climatology varies widely over a relatively small area. Using a standardized temperature threshold such as the National Weather Service-defined $32^{\circ} \mathrm{C}$ means that for southern inland locations in California, the entire summer is one long heat wave, whereas in cooler coastal locations such as San Francisco, a heat wave would register only once a decade. What matters in the context of human health risks is how extreme heat is experienced locally, which in turn depends on 
local acclimatization and what is perceived as 'normal' as opposed to excessive periods of heat.

By mid-century (2045-2054), the total number of heat wave days in coastal cities approximately doubles under B1 and triples under A1fi, with changes of three to four times for inland cities. The onset of the heat wave season is earlier, and average heat waves lasting longer. Heat wave intensity, measured here as the sum of the daily heat wave temperature threshold exceedance multiplied by the length of the heat wave in days, shows small increases ( 0 to 50 percent) for coastal LA and San Francisco, but changes of $10-300 \%$ under B1 and 130-350\% under A1fi for inland Sacramento, Fresno and $\mathrm{SB} /$ Riverside. The largest inter-scenario difference during this decade is evident in the intensity of the strongest or most extreme heat wave of the decade. For Los Angeles, intensity of the strongest heat wave of the decade changes the least, with increases of only 10-15 percent under B1 but 55-100 percent under A1fi. The change is largest for Fresno, with an increase is more than an order of magnitude larger: 2 to 5.4 times greater intensity than during the 1990s for B1 and 2.5-6.3 times greater for A1fi.

By the end of the century (2090-2099), the number of heat waves in Los Angeles is projected to increase from an average of four per year over a 14-week period in the 1990s to 7-9 events over 19-25 weeks ( $\sim 1 / 3$ to $1 / 2$ of the year, B1) or 9-13 heat waves over 3137 weeks $(\sim 2 / 3$ of the year, A1fi). This is the largest increase of all five cities; San Francisco and San Bernardino show similar trends, while inland Sacramento and Fresno show a lesser increase of only 2-3 more days under B1 and 3-8 more days under A1 fi (as shown in Fig. 8).

Although a lesser increase in heat wave events is projected for inland cities, these show a greater increase in the average length of heatwaves for a total of 7-13 days (B1) or 12-19 days (A1 fi) by the 2090s. The increase for coastal cities (with San Bernardino appearing here as being more like a coastal than an inland city) is only 6-8 days under B1 and 9-13 days for A1 fi. The net result is that inland cities will experience a very similar number of heat wave days as their coastal counterparts, but without the same degree of relief in between. There will also be a shorter break in between heat waves for Sacramento and Fresno, as their heat wave seasons are much shorter, increasing from $\sim 6$ weeks to $10-13$ weeks (B1) or 14-18 weeks (A1fi). This is in contrast to LA, which shows the longest heatwave season of 19-25 weeks (B1) and 31-37 weeks (A1fi), and San Francisco and San Bernardino with seasons lasting $\sim 50-100 \%$ longer than inland cities.

During the 1990s, the average heat wave intensity for all five cities was similar. However, average heat wave intensity increases exponentially inland, with the intensity of inland Fresno, Sacramento and San Bernardino heat waves nearly doubling that of LA and San Francisco by 2090s under either scenario (Fig. 9). As the total number of heat wave days is approximately equal, this indicates much hotter heat waves for inland cities, a conclusion supported by their higher growth rate of extreme heat waves that make up 23-54 percent (B1) and 56-84 percent (A1fi) of all heat waves by the 2090s. 


\subsection{REFERENCES}

Dettinger, M.D., D.R. Cayan, M.K. Meyer, and A.E. Jeton, 2004: Simulated hydrologic responses to climate variations and change in the Merced, Carson, and American River basins, Sierra Nevada, California, 1900-2099. Climatic Change 62, 283-317. Hayhoe, K., D. Cayan, C.B. Field,' P.C. Frumhoff, E.P. Maurer, N.L. Miller, S.C. Moser, S.H. Schneider, K.N. Cahill, E.E. Cleland, L.Dale, F. Davis, R. Drapek, R. M. Hanemann, L.S. Kalkstein, J.Lenihan, C.K. Lunch, R.P. Neilson, S.C. Sheridan, J.H. Verville, 2004: Emissions Pathways, Climate Change, and Impacts on California. Proc. National Academy of Sciences, 101, 34, 12422-12427.

Houghton, J.T., Y. Ding, D.J. Griggs, M. Noguer, P.J. van der Linden, and D. Xiaosu (eds.). 2001. Climate Change 2001: The Scientific Basis. Contribution of Working Group I to the Third Assessment Report of the Intergovernmental Panel on Climate Change. Cambridge, UK and New York, NY: Cambridge Univ. Press.

Jin, J. and N.L. Miller, 2004: An analysis of climate variability and snowmelt mechanisms in mountainous regions. J. Hydrometeorology. (Submitted).

Jin, J, N. L. Milller, S. Sorooshian, and X. Gao, 2004: Relationship between atmospheric circulation and snowpack in the western United States. Hydrological Processes. (Submitted).

Miller, N.L., K.E. Bashford, and E. Strem, 2003: Potential impacts of climate change on California hydrology. J. Am. Water Resources Association 39, 771-784.

Nakićenović, N. et al., 2000: IPCC Special Report on Emissions Scenarios. Cambridge University Press, Cambridge, United Kingdom and New York, NY, USA, 599 pp.

Pope, V.D., M.L. Gallani, P.R. Rowntree, and R.A. Stratton. 2000. The impact of new physical parameterizations in the Hadley Centre climate model-HadCM3. Climate Dynamics 16:123-146.

Washington, W.M., et al., 2000: Parallel Climate Model (PCM) Control and Transient Simulations. Climate Dynamics 16, 755-774.

5.0 Acknowledgements: Numerical model development and analysis was completed by Jiming Jin. Climate change heat analysis was completed by Norman Miller. We thank the National Center for Atmospheric Research and the Hadley Centre for making PCM and HadCM3 output available. We also thanks Katharine Hayhoe of Atmos Research for providing us with the large scale climate output for the heat analysis. We thank CEC PIER for support to Miller and Jin for this work. Work for the Department of Energy is under contract DE-AC03-76SF0098. This manuscript is Lawrence Berkeley Laboratory report LBNL-56370. 


\subsection{FIGURES}

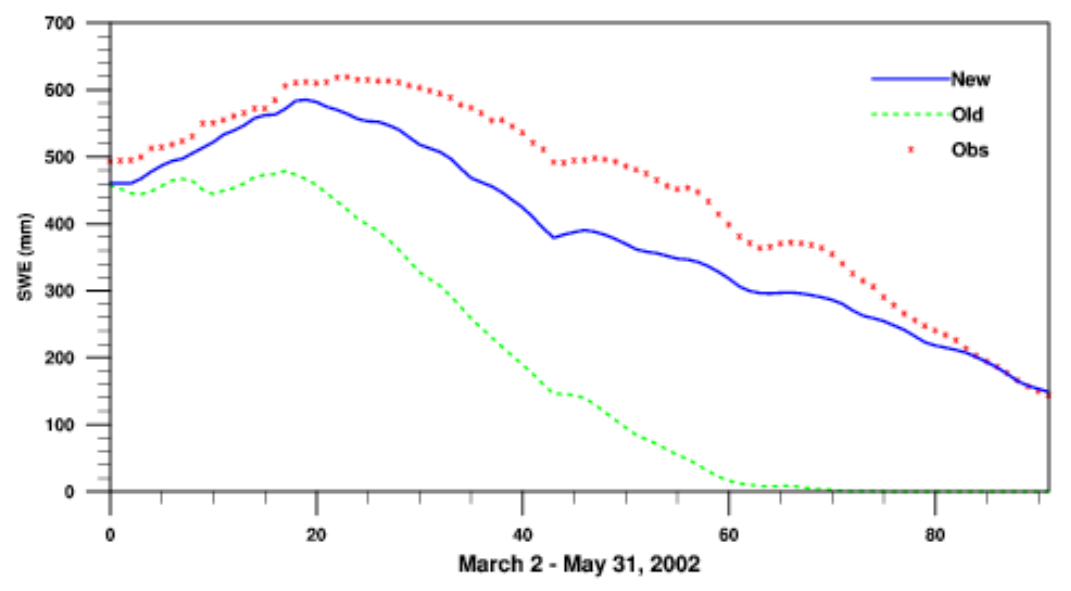

Figure 1. Comparison of the snowpack observations and simulations averaged over the 50 SNOTEL stations. The red stars represent the SNOTEL observations, the blue line is for the MM5-CLM simulations, and the green dashed line is for the MM5-NOAH simulations.

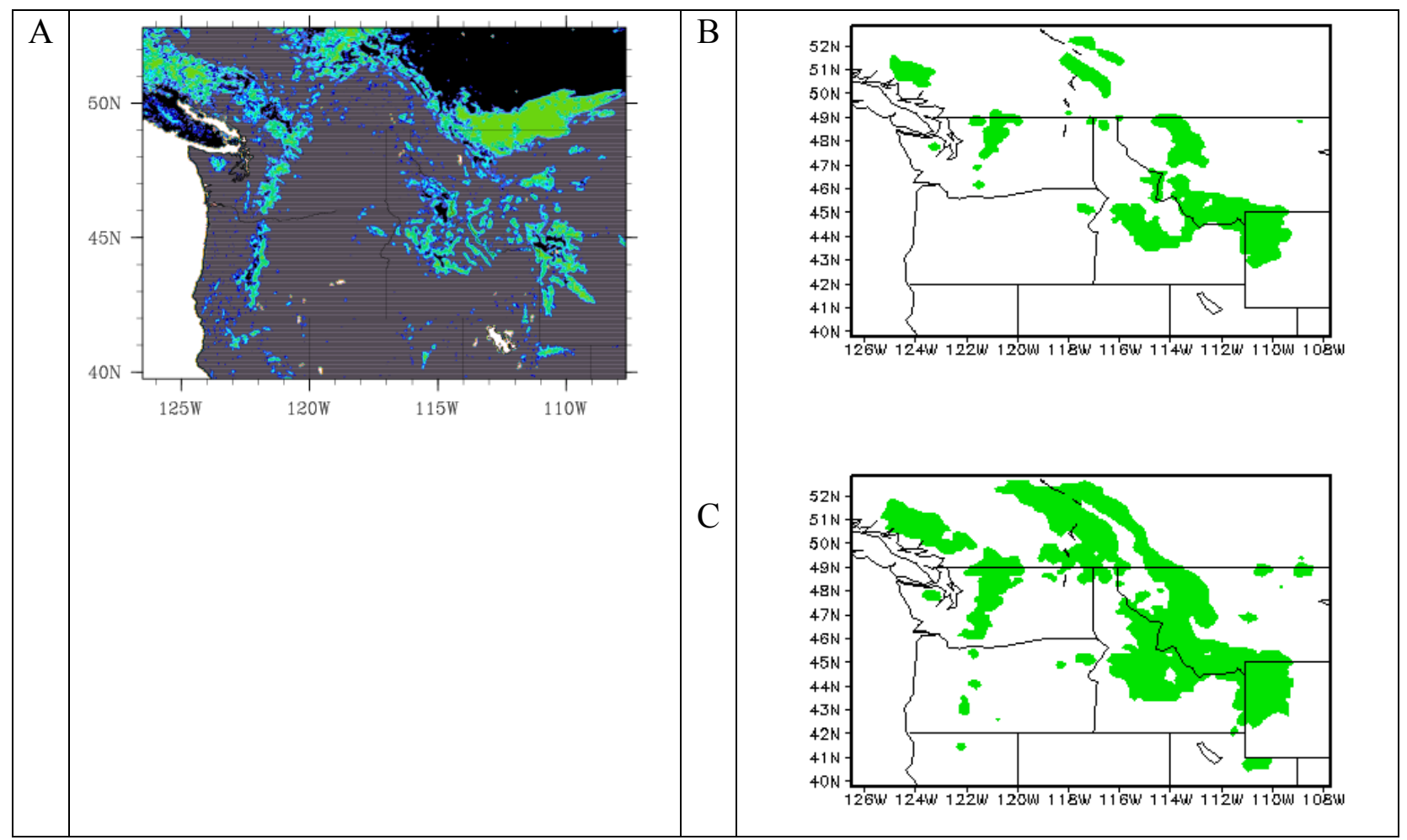


Figure 2. (A) Observed snow cover at the $5 \mathrm{~km} \times 5 \mathrm{~km}$ from the MODIS/Terra satellite, (B) snow cover simulation at the $20 \mathrm{~km}$ resolution from MM5-NOAH, and (C) snow cover simulation at the $20 \mathrm{~km}$ resolution from MM5-CLM.

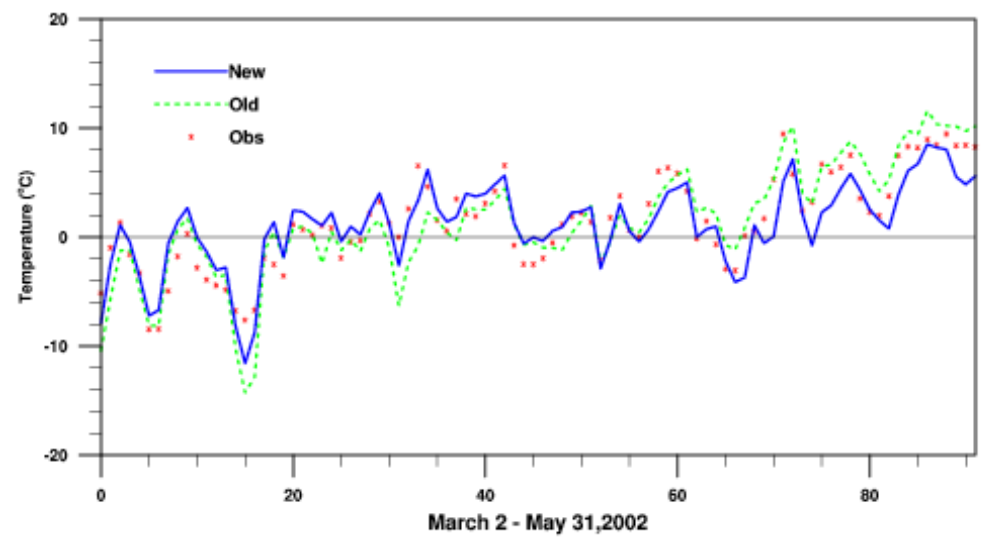

Figure 3. The same as in Figure 1, but for 2 meter height air temperature.

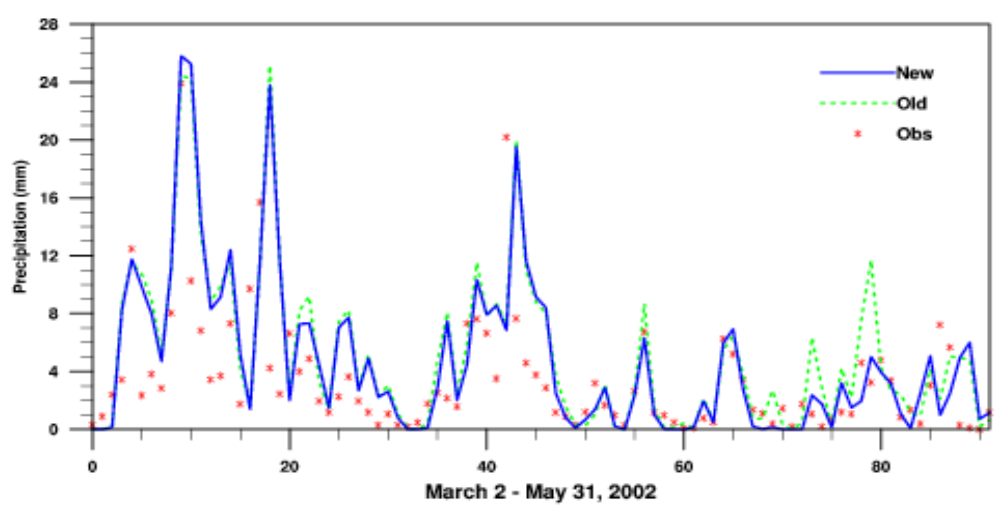

Figure 4. The same as in Figure 1, but for precipitation.

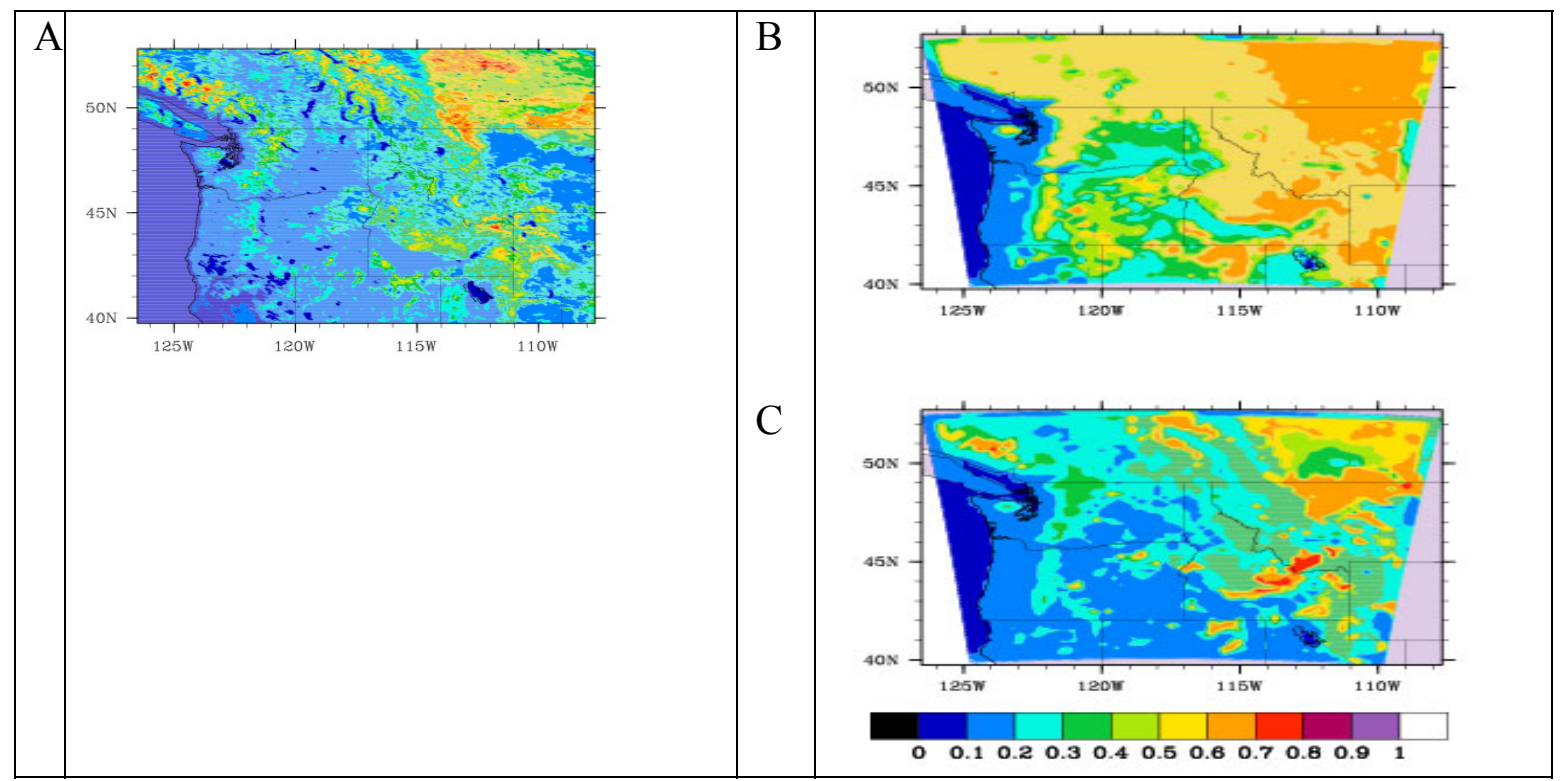


Figure 5.

satellite simulated

NOAH, CLM

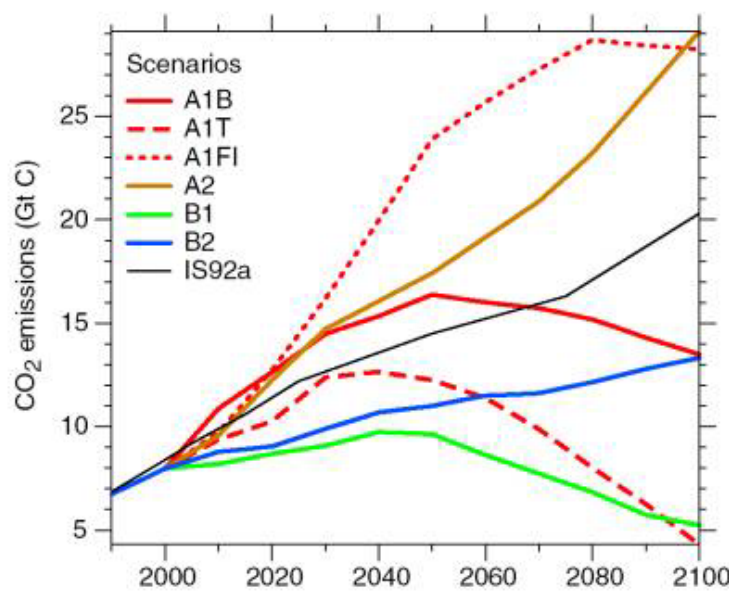

(A) The observed SeaWiFS surface albedo, (B) the surface albedo from MM5and $(\mathrm{C})$ the simulated MM5surface albedo.

Figure 6. Carbon dioxide emissions projections corresponding to the SRES emissions scenarios A1fi (red dashed line) and B1 (green solid line) used in this analysis.
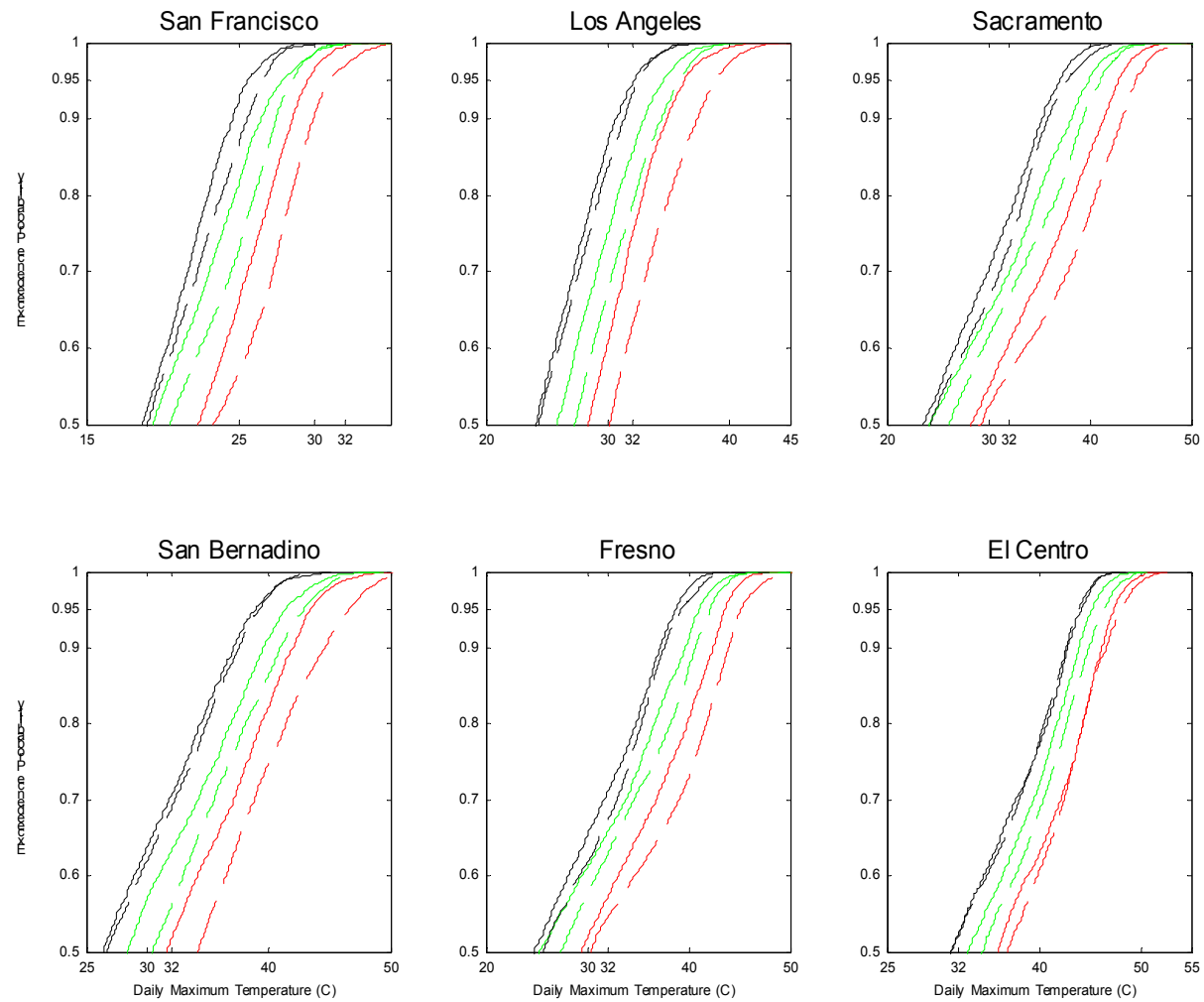
Figure 7. Temperature exceedance probabilities for PCM (dashed) and HadCM3 (solid) projections under emission scenarios A1fi (Red) and B1 (Green) for 2090-2099 for San Francisco, Los Angeles, Sacramento, San Bernadino, Fresno, and El Centro.

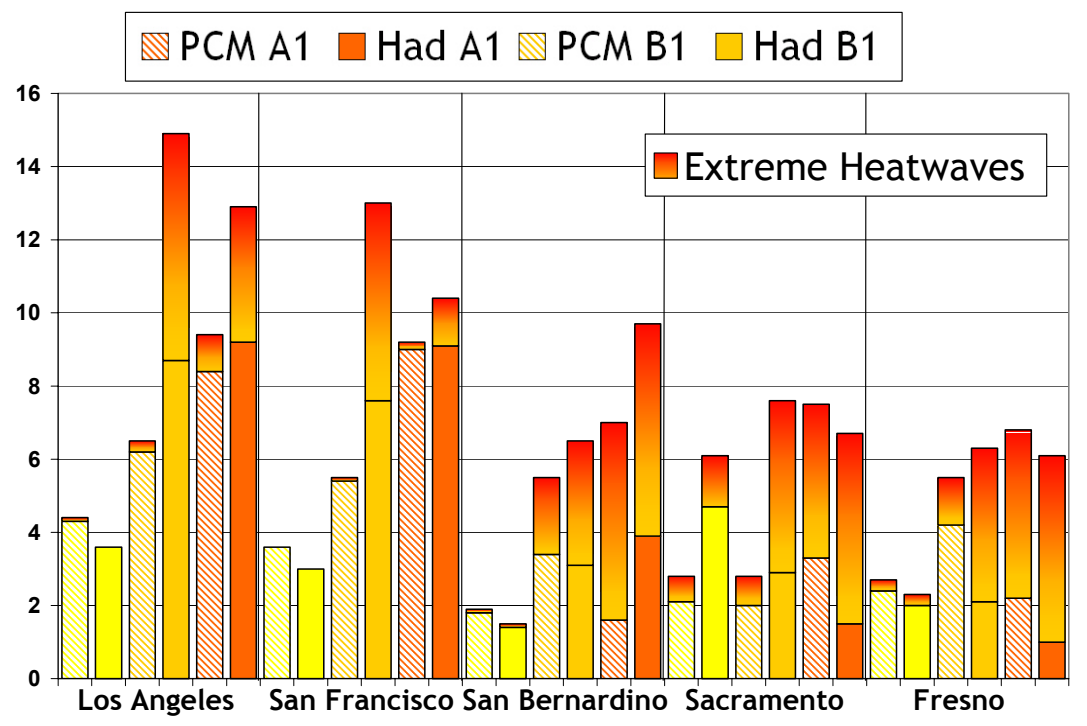

Figure 8. Average annual number of heat wave events for 1990-1999 and 2090-2099 for the PCM and HadCM3 A1fi and B1 scenarios for Los Angeles and Sacramento. Yellow bars show 1990's averages for each model, while gold bars indicate projections for the B1 scenario and orange bars projections for the A1fi scenario. Heat waves are divided into 'regular' (occurring an average of 3 times per year or 30 times per decade during the reference period 1961-1990) and 'extreme' (occurring 1-2 times per decade during 1961-1990). Extreme events currently constitute $\sim 2$ percent of all heat waves but this proportion is projected to increase, particularly under the A1 fi scenario and for the inland location. 


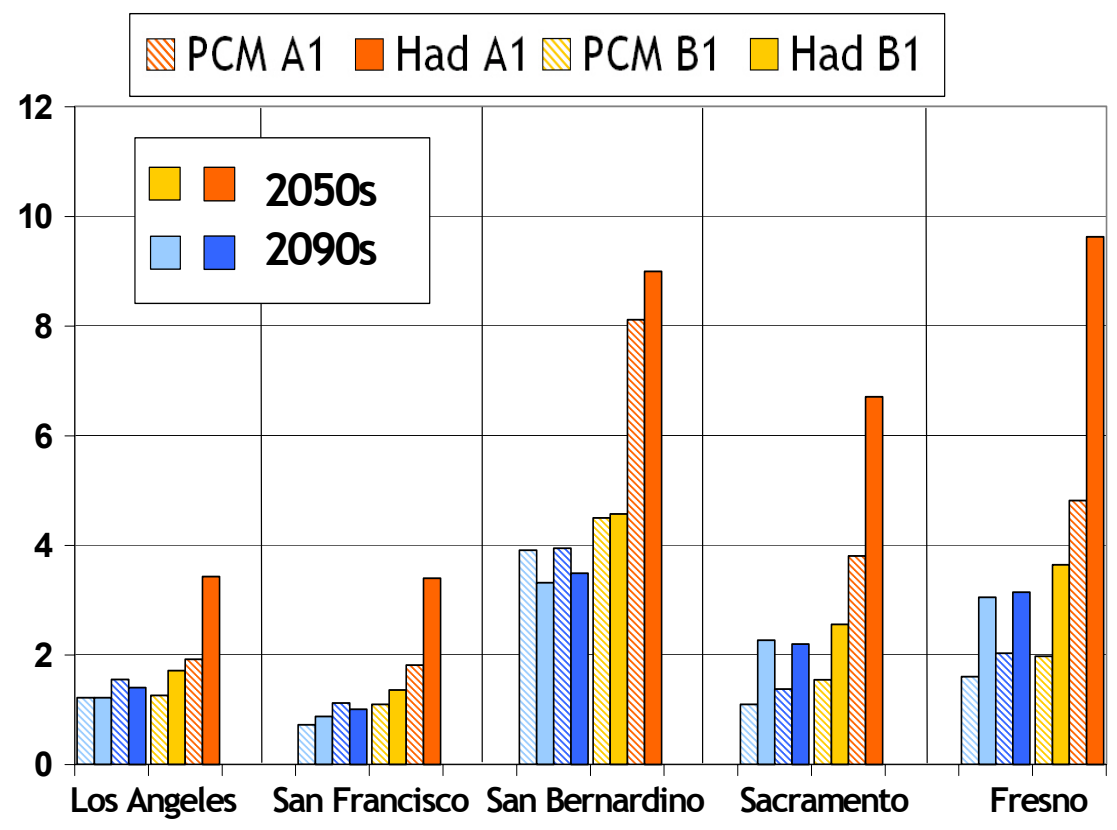

Figure 9. Average heat wave intensity (sum of temperature exceedances multiplied by length of heat wave in days) for all five cities for the PCM and HadCM3 A1fi and B1 scenarios. Shown are the differences relative to 1990-1999 average for 2045-2054 and 2090-2099 where a value of one means the intensity is equal to that experienced during the 1990s. Intensity increases are significantly greater under the A1fi scenario and for the inland cities.

\begin{tabular}{|lccc|}
\hline & \multicolumn{2}{c}{$\begin{array}{c}\text { Regular } \\
\text { heatwaves }\end{array}$} & $\begin{array}{c}\text { Extreme } \\
\text { heatwaves }\end{array}$ \\
\hline HadCM3 & PCM & Both models \\
\hline San Francisco & 26.0 & 26.2 & 32.7 \\
Los Angeles & 32.2 & 32.3 & 38.2 \\
San Bernadino & 38.8 & 39.1 & 42.1 \\
Fresno & 38.9 & 39.1 & 42.1 \\
Sacramento & 37.2 & 37.2 & 41.0 \\
\hline
\end{tabular}

Table 1. Threshold temperatures for heat wave identification, determined by iteration over the reference period 1961-1990 such that an average of 30 "regular" and 1-2 "extreme" heatwaves occur per decades.

\subsection{PRESENTATIONS}

Bastidas, L.A., S. Li, and N.L. Miller, 2003: A Scheme for Application of Non-Uniform Grid Scales for Land Surface Modeling. The American Geophysical Union Conference, December, 2003, San Francisco, CA.

Jin. J., and N. L. Miller, 2003: A space-time correlation analysis of ENSO and snowpack in the western United States. NOAA Climate Diagnostic Workshop, October, 2003. Reno, Nevada. 
Jin, J., and N. L. Miller, 2003: A mesoscale study of impact of snowpack on climate variability over the Sierra Nevada Mountains. The American Geophysical Union Conference, December, 2003, San Francisco, CA.

Jin, J, and N L. Miller 2004 : A relationship between atmospheric circulation and snowpack in the western United States. The America Meteorology Society Conference, January, 2004, Seattle, CA.

Jin J., and N. L. Miller, 2004: Coupling an advanced land surface model in a regional climate model to improve snow simulation. The 21th Annual Pacific Climate Workshop, March, 2004, Pacific Grove, CA.

Jin J., and N. L. Miller, 2004: On the development and testing of a coupled regional climate model with an advanced land surface model. The American Geophysical Union Spring Conference, May, 2004, Montreal, Canada.

Jin J., and N. L. Miller, 2004: An analysis of snow simulations in a regional climate model with an advanced snow scheme. The Mountain Climate Sciences Symposium. May, 2004, Lake Tahoe, Ca.

Maxwell, R.M. and N.L. Miller, 2003: Development of a Coupled Land Surface and Ground Water Model for use in Watershed Management. The European Geophysical Society Conference, May, 2004, Nice, France.

Miller, N.L. 2003: Climate Impacts Research. Institute for Research on Climate Change and its Societal Impacts, Yosemite, Aug, 2003.

Miller, N.L., 2003: California Water Resources Research, CEC Sept 2003 Coordination Meeting. Sacramento.

Miller, N.L. 2003: Climate change impacts on California hydrology, Testimony to the California Senate, Nov. 2003, Sacramento.

Miller, N.L. 2004: Climate change sensitivity study of California hydrology, Dept. of Civil and Environmental Engineering and Utah Water Research Laboratory, Utah State University, 15 March 2004

Miller, N. L. and J. Jin, 2004: Snow simulations over the Columbia River basin using a coupled regional climate. The European Geophysical Society Conference, May, 2004, Nice, France.

Miller, N.L., 2004: Recent advances and analyses in land surface-subsurface processes. First Annual California Climate Change Conference, June 2004, Sacramento. 